\title{
From gastric aspiration to airway inflammation
}

\author{
I.A. Brownlee1, A. Aseeri1, C. Ward2, J.P. Pearson 1
}

ABSTRACT: From gastric aspiration to airway inflammation. I.A. Brownlee, A. Aseeri, C. Ward, J.P. Pearson.

The airways are poorly protected from potentially damaging agents contained within gastric contents. While digestive factors are obvious damaging agents, gastric aspiration may also deliver microbial agents, cytokines or food antigens to airway tissues. Direct damage or the triggering of the inflammatory cascade by gastric aspiration is believed to drive airways disease onset and/or progression.

Evidence exists from experimental models demonstrating direct instillation of damaging factors to a range of airways epithelia causes damage and/or an inflammatory response. Clinical longitudinal studies have also noted an association between the presence of biomarkers of reflux in airways samples and disease progression. A shared pathophysiology of many chronic airways diseases is a more negative intrathoracic pressure. Such changes would drive an in- creased abdominothoracic pressure gradient. These changes in respiratory mechanics mean that chronic lung disease patients may be predisposed to reflux and subsequent aspiration. Therefore, it appears that gastric aspiration and airways disease progression may be linked not solely as cause and effect, but seemingly within a vicious cycle.

A range of physiological factors govern both occurrence of gastric reflux into the pharynx/larynx and could also increase the susceptibility of certain individuals to disease progression. A range of long-term surgical and pharmacological intervention studies are necessary to test the benefit of such therapies in reducing disease progression or driving symptom improvement. Such studies may be hampered by the reliability of available therapies in halting gastric aspiration and the difficulty in the clinical or biochemical assessment of gastric aspiration. Monaldi Arch Chest Dis 2010; 73: 2, 54-63.

Keywords: Pepsin, Aspiration, Reflux, Epithelial mesenchymal transition, Inflammation, Bile salts.

1 Institute for Cell \& Molecular Biosciences, Medical School, Newcastle University, Newcastle-upon Tyne, NE2 4HH,

2 Institute of Cellular Medicine, Medical School, Newcastle University, Newcastle-upon Tyne, NE2 4HH, UK.

Correspondence: Prof Jeffrey P. Pearson, Institute for Cell \& Molecular Biosciences, Medical School, Newcastle University, Newcastle-upon Tyne, NE2 4HH, UK; e-mail: j.p.pearson@ncl.ac.uk

\section{Introduction}

The term aspiration refers either to the inhalation of food from the oropharynx or gastric contents that have moved up the oesophagus in retrograde fashion [1]. An association between aspiration and inflammatory airways disease was first suggested during the 1960s and 1970s (e.g. [2-5]). Aspiration by either route will lead to the presence of increased amounts of potentially damaging agents into the airways, which is hypothesised to drive the onset and/or progression of a wide spectrum of pathological conditions that affect the lungs and airways [6,7]. During gastric aspiration, potentially damaging digestive factors from the stomach (via the oesophagus) pass into the relatively unprotected airways. Gastric aspiration is therefore hypothesised as being a prime causative candidate for almost every chronic upper airways disease. This hypothesis has proved difficult to test, due to both the difficulties of assessing the presence of reflux clinically or diagnostically [810], alongside the fact that pharmacological and surgical interventions for reflux can only reduce, but not abolish, the occurrence of gastric content reaching the oesophagus/airways.
The symptomology of airways disease is as divergent as the potential aetiologies. One common feature is the presence of an inflammatory response within the affected mucosal surfaces [11-15]. The process of inflammation involves a complex cascade of cellular, molecular and systemic events that are aimed at benefitting the clearance of noxious agents from the mucosal surface. In most pathophysiological cases, the inflammatory response appears to be in excess of the normal state, and is believed to play a role in disease progression. The inflammatory response is not necessarily in proportion to the damaging potential of the initiating agent, and can drive further damage to the surrounding tissues [16].

Previous studies would suggest a high incidence of gastric aspiration in chronic diseases of the lungs and upper airways [17-21]. In some cases, associations have been made between measured occurrence of biomarkers of reflux and disease progression [22] or proxy measures of the inflammatory response [23, 24]. A number of observational studies have also noted an increased co-morbidity between oesophagitis and various airways diseases [25-27]. Perhaps the 
most commonly held beliefs are a) aspiration (particularly the reflux of gastric contents) is a potential initial drive for disease progression and b) symptomatic individuals may have more frequent/injurious aspiration events than non-symptomatic individuals. While these hypotheses appear sound, they both neglect key issues within the association of aspiration and airway inflammation, and their impact on disease progression. The remainder of this review will discuss the interplay between gastric aspiration and airways inflammation in greater detail.

\section{Aspirate content and lung inflammation}

While direct aspiration of ingested food can present antigens or bacterial load into the airways, gastric aspiration has further potential modes of antagonism of the airways' mucosa. Firstly, the presence of digestive factors, including enzymes, bile acids and other detergents (e.g. lecitihins) and gastric acid have all previously been shown to have the potential to damage airways mucosa directly [28-31]. The main digestive protagonists from gastric juice that have previously been suggested to drive mucosal damage are gastric acid, pepsin and bile acids.

Gastric acid and pepsin are secreted by the parietal cells and chief cells respectively in the stomach. These gastric secretions are important both in the early stages of protein digestion, but may also act as an important innate barrier to microbes entering the body orally [32-35]. Bile acids are produced by the liver conjugated to glycine or taurine and secreted into the small intestine where they act to emulsify dietary lipids to aid fat digestion and absorption [36, 37]. Small intestinal contents are believed to frequently reflux from the duodenum into the stomach, with well over $50 \%$ of gastro-oesophageal reflux disease (GORD) patients reported to experience the movement of mixed gastric and duodenal contents up the oesophagus [38]. A range of small intestinal enzymes could also end up in the stomach by this route. If they are not degraded or denatured during the retrograde passage from duodenum to stomach to the aerodigestive tract. For example trypsin is unaltered by exposure to pepsin at $\mathrm{pH} 4.0$, but inactivated by exposure to pepsin at $\mathrm{pH} 2.0$, they also have the potential to cause mucosal damage.

Aspiration of digestive products may also lead to an indirect drive for mucosal inflammation. Firstly, homogenised and partially hydrolysed foods may act as a more amenable substrate to bacterial species already occurring within the airways. Secondly, the hydrolysis and denaturation of dietary proteins during normal digestion could lead to the appearance of previously sequestered antigen. The potential mechanisms for damage by gastric aspirate are summarised in table 1.

Pharmacological therapies for acid suppression have been shown to greatly reduce oesophageal exposure to low $\mathrm{pH}[39,40]$. Such therapies will act to reduce the total volume of the gas- tric juice [41-43], but may act to effectively increase the concentration of pepsin, bile acids and other putatively damaging digestive factors due to the lower volume of gastric secretion. Further from this, recent studies have demonstrated an increased incidence of intestinal infection and communicable diseases following acid suppression [44-48]. This is due to an overgrowth of oral-type bacteria within the stomach [49] as a result of the decreased innate immunity with the removal of the acid barrier. Subsequent aspiration events under such therapies may therefore be of lower total volume and higher $\mathrm{pH}$, but may have a higher concentration of other putatively damaging endogenous and microbial factors.

Direct damage of the airways mucosa by gastric aspiration is the most obvious trigger for an inflammatory response. However, a number of key routes for gastric aspiration-driven inflammation are also hypothesised. The majority of the airways epithelium is lined by a functional mucus barrier that acts to reduce mucosal exposure of damaging inhaled agents, as well as entrapping such agents and facilitating their removal through the process of mucociliary clearance $[50,51]$. As such, efficient mucus barrier function plays a vital role in the innate defence of the airways [50]. Many airways diseases are characterised by mucus hypersecretion $[52,53]$. This can be a result of increased fluid output, or increased release of mucin granules by the epithelial goblet cells and/or increased gland-based secretion (driven by secretagogues, such as IL-8). If the mucus layer becomes too rheologically thick or thin, mucociliary clearance is greatly reduced, leaving the underlying tissues more susceptible to damage and infection [50].

Inflammatory responses to damaging agents may also be partly driven by the presence of specific receptors within the epithelium. In the case of factors like bacterial lipopolysaccharides, such receptor-mediated pathways are fairly well researched $[54,55]$ and appear to be mediated by toll-like receptor activation and a subsequent inflammatory cascade The triggering of nociceptors such as the capsaicin receptor in the airways by low $\mathrm{pH}$ is also well documented [56, 57]. Evidence would also suggest that recurrent cough could also cause airways damage/act to mediate local inflammatory pathways. In a group of patients with chronic non-productive cough, a subset of individuals who did not have asthma or acidic reflux ("idiopathic" non-productive coughers) had elevated levels of mast cells within their bronchoalveolar lavage fluid in comparison to nonsmoking, healthy controls [58]. Recent preliminary data have also suggested that there may be specific receptors that are triggered by the presence of gastric juice factors, such as pepsin and bile $[59,60]$.

A summary of these pathways is suggested in figure 1 below.

Recent interest in the field has noted that retrograde movement of gas boluses from the stomach may also be an important route of gastric aspi- 
ration [61, 62]. While this would not deliver the same volume of gastric contents to the airways, it is believed that aerosolised vapour could act to coat airways mucosa. The aerosolised content would be expected to contain similar damaging agents to those outlined in table 1 .

Table 1. - Potential mediators of airways inflammation and damage within gastric contents

Directly damaging agents Agents released by digestion

Digestive factors (i.e. enzymes, bile, acid)

Ingested, salivary or gastric microbes

Food particles

Food antigen
Digested macronutrients

Antigen formed by dietary protein hydrolysis

Microbe release from gastric bolus






\section{Reflux pathophysiology}

Reflux of gastric contents is an episodic event in both the physiological and pathophysiological state [63]. 24-h ambulatory impedance monitoring of 72 healthy adults [64] demonstrated that the median number of gastro-oesophageal reflux events to occur in a day was 44 , with a great deal of inter-individual variation (the $25^{\text {th }}$ and $75^{\text {th }}$ percentiles were 25 and 58 events respectively). These episodes are characterised by increased gastric motility, a transient reduction in lower oesophageal sphincter tone and increased intragastric pressure. Recent literature has focussed on a central role for transient lower oesophageal sphincter relaxations (tLOSRs) [65-69]. While evidence would suggest that tLOSRs are no more frequent in GORD patients than asymptomatic volunteers, the likelihood that GORD patients will reflux during the period of sphincter relaxation is almost twice as high [69]. While significantly higher occurrences of reduced lower oesophageal pressure are noted in GORD patients complicated with severe hiatal hernia [70,71], it must be noted that this particular patient group is not indicative of GORD patients per se [63]. Functionally, reflux from the stomach to the oesophagus has the potential to occur whenever the intragastric pressure exceeds lower oesophageal sphincter pressure. Manometry studies have noted a higher pressure gradient across the lower oesophageal sphincter in GORD patients than non-symptomatic controls, with the difference in gradient owing to a higher gastric pressure [72]. Recent assessments of gastrointestinal motility have also suggested that the position of the "acid pocket" (i.e. secreted gastric juice that sits above the meal bolus) in relation to the diaphragm [73] may drive reflux. Further functional studies have suggested that the occurrence of retrograde waves of peristalsis up the oesophagus appears to be propagated by the occurrence of tLOSRs [65], which could act to further increase aspiration events. A previous study in non-symptomatic volunteers noted that barostat distension of the stomach resulted in increased number of tLOSRs than distension to the same degree by an ingested meal [68]. This would suggest that the drive for gastric motility given by postprandial luminal content may reduce the frequencies of tLOSRs.

Intragastric pressure is controlled by a complex array of neurohumoral pathways that govern lower oesophageal and pyloric sphincter tone, gastric compliance, gastric secretion volume and gastric motility. Alongside vagal innervation, three main hormonal drives may govern all of these factors [74]. Cholecystokinin (CCK) release from the duodenal I cells is a major drive for reduced gastric emptying, while gastrin release from gastric $\mathrm{G}$ cells increases gastric mixing. Both of these factors could drive an increased intragastric pressure. At the same time, motilin release from intestinal enteroendocrine cells acts to increase the rates of gastric emptying, and thus would be expected to decrease intragastric pres- sure. Previous reviews have suggested the potential of these agents and their receptors as targets for reflux therapy $[75,76]$.

Reflux symptoms are prevalent in the majority of airways diseases. For instance, previous reports would suggest that around $80 \%$ of adult asthmatics have symptoms of reflux [77, 78]. It must be noted that the association between gastric aspiration and airways pathophysiology is often hypothesised to be a result of aspiration driving the disease process. However, the association between the two processes in not fully defined, and a number of researchers have suggested that the negative intrathoracic pressure caused by a result of airways obstruction and/or respiratory distress may act to drive reflux by increasing the likelihood of gastric contents refluxing into the oesophagus [78-80]. A preliminary temporal association study was carried out between episodes of coughing/wheezing in asthmatics and reflux occurrence, as assessed by pH-metry in 2001 [81]. Within this population group, reflux events preceded cough events by less than 2 minutes $40 \%$ of total cough events per patient, with only $6 \%$ of reflux events being preceded by cough events over the same time-course. These figures were elevated to $50 \%$ and $12 \%$ respectively when a five minutes inter-event time cut-off was applied. In more recent studies where impedance monitoring has been used to assess reflux in paediatric asthma [82], cystic fibrosis [83] and chronic cough [84] patients. In all cases within these studies, it must be noted that an appreciable number of cough events were associated with reflux events within two of these studies, $26.6 \%$ total of events within a 5-minute window [82] in paediatric asthmatics and $30.6 \%$ within a two-minute window in chronic cough patients [84]. Such temporal studies may not best represent the interplay between intrathoracic pressure and reflux/aspiration. In terms of intrathoracic pressure mediating reflux, cough represents a short-term negative intrathoracic pressure change, as opposed to a more uniform, long-term change towards lower pressure seen in disease processes where there is chronic lung obstruction. In terms of aspiration driving airways symptoms, cough is an immediate response, believed to be triggered by a range of cough receptors [85]. As there are previous reports of refluxers having reduced laryngeal sensitivity [86-89], it is perhaps unsurprising that the cough reflex is not always elicited in response to gastric aspiration. Over a short time scale, gastric aspirate may not be damaging enough to the airways mucosa to drive a relevant clearance response such as cough. As previously discussed, aspiration of aerosolised gastric contents may also lead to damaging material entering the airways, that would be considerably less likely to elicit an immediate cough reflex than a large volume reflux event. One previous study used a canine model to assess the impact of balloon-catheter-induced upper airways obstruction on reflux occurrence (assessed by $\mathrm{pH}-$ metry). Within this study, there was a strong and significant positive correlation $(\mathrm{R}=0.928, \mathrm{P}=$ 
0.023 ) between the change towards a more negative intrathoracic pressure and percentage of time proximal $\mathrm{pH}$ was below 4 in five dogs [90]. While this study is low in numbers, it may model how long-term pressure changes affect gastric aspiration.

From the above, there is evidence that the development of an abdominothoracic pressure gradient may drive further reflux and gastric aspiration, with consequent worsening of disease symptoms. While there is no conclusive proof as to whether airways symptoms drive reflux or vice versa, it is perhaps more likely to consider that these events could conspire to worsen chronic disease progression through a vicious cycle [91]. Preliminary longitudinal data from our own group would suggest that reflux is a common occurrence post lung transplantation, even at timepoints when lung mechanics should be close to normal [92].

Our group has consistently shown that pepsin, as a marker of gastric aspiration, is elevated in lung transplant recipients $[21,22]$ and has been associated with neutrophilic airway inflammation and pathologist graded acute rejection [22]. Acute airway rejection is known to be associated with airway inflammation and to constitute a risk factor for chronic allograft dysfunction, recognised physiologically by fixed airflow limitation (Bronchiolitis Obliterans Syndrome: (BOS) [93]. The pathology underlying BOS involves inflammation and airway remodelling and fibrosis [93-95]. This pattern of airway damage, as in the case of reflux and aspiration, is implicated in the progression of a number of airways diseases including asthma and COPD [96]. In lung allografts, this can be very aggressive and is the main reason for the chronic loss of lung allografts [93]. In other more common lung diseases such as COPD the pattern of airway injury develops over a longer time frame.

One potential link between aspiration and airways remodelling is perturbation of TGF $\beta$ homeostasis. TGF $\beta$ is a pleiotropic growth factor (reviewed elsewhere $[16,97]$ ) that is implicated in both airway repair and pathophysiology, and which is elevated in airway disease including BOS post transplantation [98].

We have shown that TGF $\beta$ can initiate epithelial mesenchymal transition (EMT) in epithelial cells from lung allografts [99]. In EMT, epithelial cells lose epithelial characteristics adopting a mesenchymal, fibroblast phenotype which may cause airway fibrosis through the production of collagen. The process of EMT has been documented in lung development, metastatic disease and a range of other settings involving organ fibrosis [100]. Consistently TGF $\beta$ is recognised to be a prototypical drive for EMT and it is therefore of interest that bile acid challenge of human air-

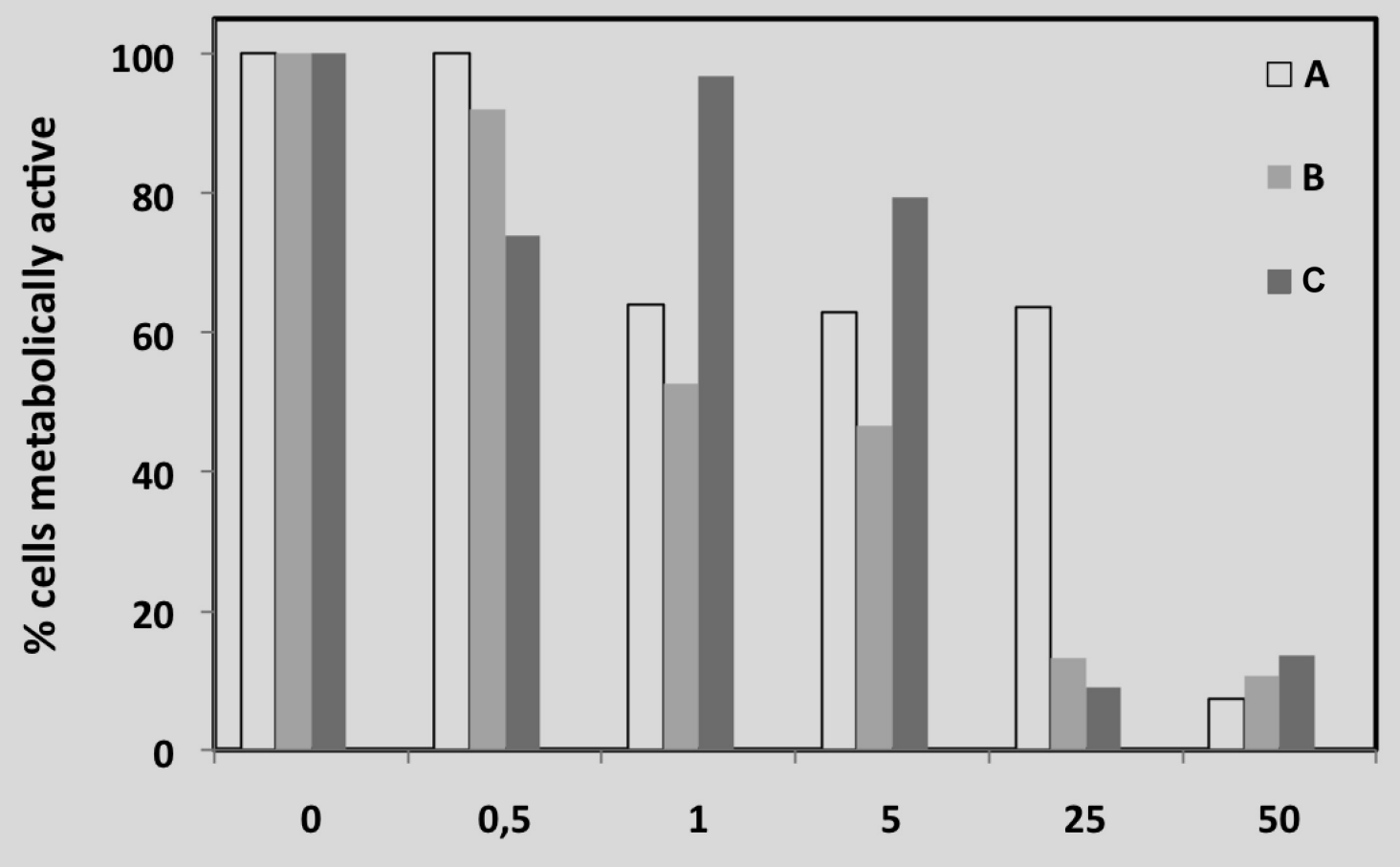

Lithocholate concentration $(\mu \mathrm{M})$

Fig. 2. - The effect of varying levels of lithocholic acid on cell viability in primary lung epithelial cultures from 4 separate lung transplant recipients (here labelled A - C), 6 - 15 months post-transplantation. Cell viability (i.e. \% cells metabolically active) was assessed by CellTiter-Blue cell viability assay (Promega. Madison, WI) [115, 116]. 
way epithelial cells has been shown to lead to the release both of inflammatory cytokines and TGF $\beta$ [101]. Most TGF $\beta$ is held in an in-active latent form. This may be activated through protease release from inflammatory cells, as well as directly by stomach acid. Type IV collagenases such as MMP-9 are also released in the inflammation with which aspiration is associated. Damage of airway epithelial basement membranes, which contain type IV collagen, is also known to promote EMT [100].

In addition to ex vivo studies on primary airway epithelial cells suggesting the potential for EMT in lung allografts, we have also shown that airway biopsies from stable lung transplant recipients express markers of the EMT proteome [99, 102]. Overall aspiration may be linked both to airways inflammation and remodelling/fibrosis. This potential linkage requires further appropriate translational research [103].

\section{Increased susceptibility to aspiration-induced airways damage}

Previous studies in non-symptomatic individuals would suggest that reflux into the oesophagus and even the pharynx is a frequent occurrence within normal life [104-107]. It might therefore be expected that gastric aspiration is also an occurrence that most individuals will have experienced. Assessment of bronchoalveolar lavage fluid in individuals asymptomatic of upper airways disease suggests that biomarkers of gastric aspiration can occur at low but detectable levels in 2 of 4 healthy individuals [22]. Some background levels of pepsin may be present in the broncho-alveolar lavage fluid of healthy individuals, as pepsinogen $\mathrm{C}$ (a precursor of human pepsin 5 and 6 ) has previously been reported to occur in type 2 alveolar cells [108]. While this data would suggest that gastric aspirate does not occur as frequently or to the same degree in a healthy population, it is important to consider that there may be other factors that predispose some individuals to airways injury as a result of gastric aspiration, either as a result of increased volume of aspirate reaching the airways, or due to a lack of defence mechanisms against aspirate-induced inflammation or injury. Data from the authors' laboratories would suggest that primary cell cultures of lung epithelia from different individuals react differently to insults from putatively damaging agents in gastric aspirate, such as the secondary bile acid lithocholic acid. While all cultures appear to be close to completely unviable at the highest concentration of lithocholate used (i.e. $50 \mu \mathrm{M}$ ), the drop-off of viable cells numbers follows a different gradient between individuals.

The data above are suggestive of genetic variability in the inflammatory response caused by such mediators of damage. Previous studies have also suggested that certain patients groups who are more or less susceptible to reflux-mediated disease tend to show specific genotype [17], or differential expression of a specific genes involved in airway protection [28, 109, 110]. While such studies would give credence to genetic predisposition as an important factor in aspiration-driven disease progression, it is important to consider that "susceptibility" may also come about as a result of temporal, anatomical or physiological changes in airways functionality.

In general, increased airways damage or inflammation as a result of aspiration is likely to be as a result of decreased defence against aspiration, or reduced clearance rates of damaging agents that are delivered to the mucosa. As described above, previous studies have suggested an elevated threshold for laryngeal sensitivity in refluxers [8689], which is higher than in asymptomatic individuals [111]. A less sensitive larynx would not perform its respiratory defence mechanisms [112, 113] as well as normal upon exposure to reflux. As a result, if the larynx were insensitive to contact with gastric contents, gastric aspiration would be more likely to occur. Factors such as vagal damage (e.g. following lung transplant surgery [114]) may also drive an increased incidence of gastric aspiration by affecting aerodigestive tract motility, and may also reduce cough and mucociliary clearance. Previous events resulting in damage or an inflammatory response in the airways could lead to an increased likelihood of subsequent damage as a result of gastric aspiration insult. This could be as a result of a loss of the innate barrier function of airways mucus, or because the underlying mucosa has become easier to penetrate. In a similar fashion, loss of effective mucociliary clearance will result in increased mucosal exposure to the damaging agents in gastric aspirate.

\section{Future work}

Current evidence is indicative of an association between airways disease progression, inflammatory processes and gastric aspiration. The next step from a clinical perspective may be the development and implementation of pharmacological or surgical interventions in the relevant patient groups, targeted at reducing gastric aspiration rates with objective measures of airways disease as the primary outcomes in adequately powered, controlled studies. In conditions where improvement of disease symptoms is unlikely (e.g. idiopathic pulmonary fibrosis), a reduction in disease progression rates may be the most relevant outcomes to measure. Such studies will be demanding and necessitate the collaboration of both gastroenterology and pulmonary specialists, and may be hampered by the difficulties in assessing occurrence of gastric aspiration/reflux clinically. Biochemical analysis of biomarkers of gastric aspiration may be a useful predictive surrogate of gastric aspiration, but further work is necessary to characterise how long such biomarkers occur within the airways following an aspiration event. Methodological standardisation is an important requirement. 


\section{References}

1. Marik PE. Aspiration pneumonitis and aspiration pneumonia. New Engl J Med 2001; 344: 665-671.

2. Awe WC, Fletcher WS, Jacob SW. The pathophysiology of aspiration pneumonitis. Surgery 1966; 60: 232239.

3. Grimshaw C, Morrell MT. A new operation of internal closure of the larynx for separation of the air and food passages. Thorax 1968; 23: 92-93.

4. Lindeman RC. Diverting the paralyzed larynx: a reversible procedure for intractable aspiration. Laryngoscope 1975; 85: 157-180.

5. Wynne JW, Modell JH. Respiratory aspiration of stomach contents. Ann Intern Med 1977; 87: 466-474.

6. Harding SM. Gastroesophageal reflux and asthma: Insight into the association. J All Clin Immunol 1999; 104: 251-259.

7. Nishino T. Swallowing as a protective reflex for the upper respiratory tract. Anesthesiology 1993; 79: 588601.

8. Richter JE. The many manifestations of gastroesophageal reflux disease: presentation, evaluation, and treatment. Gastroenter Clin North Am 2007; 36: 577599.

9. Fass R. Symptom assessment tools for gastroesophageal reflux disease (GERD) treatment. $J$ Clin Gastroenter 2007; 41: 437-444.

10. Vaezi MF. Are there specific laryngeal signs for gastroesophageal reflux disease? Am J Gastroenter 2007; 102: 723-724.

11. Bousquet J, Chanez P, Lacoste JY, et al. Eosinophilic inflammation in asthma. New Engl J Med 1990; 323: 1033-1039.

12. Davis PB, Drumm M, Konstan MW. Cystic fibrosis. Am J Respir Crit Care Med 1996; 154: 1229-1256.

13. Hogg JC, Chu F, Utokaparch S, et al. The nature of small-airway obstruction in chronic obstructive pulmonary disease. New Engl J Med 2004; 350: $2645-$ 2653.

14. Selman M, King TE, Jr, Pardo A. Idiopathic pulmonary fibrosis: Prevailing and evolving hypotheses about its pathogenesis and implications for therapy. Ann Intern Med 2001; 134: 136-151.

15. Yousem SA, Berry GJ, Cagle PT, et al. Revision of the 1990 working formulation for the classification of pulmonary allograft rejection: Lung Rejection Study Group. J Heart Lung Transplant 1996; 15: 1-15.

16. Charo IF, Ransohoff RM. Mechanisms of disease: The many roles of chemokines and chemokine receptors in inflammation. New Engl J Med 2006; 354: 610-621.

17. Blondeau $\mathrm{K}$, Mertens $\mathrm{V}$, Vanaudenaerde BA, et al. Gastro-oesophageal reflux and gastric aspiration in lung transplant patients with or without chronic rejection. Eur Respir J 2008; 31: 707-713.

18. Ozmen S, Yucel OT, Sinici I, et al. Nasal pepsin assay and $\mathrm{pH}$ monitoring in chronic rhinosinusitis. Laryngoscope 2008; 118: 890-894.

19. Potluri S, Friedenberg F, Parkman HP, et al. Comparison of a salivary/sputum pepsin assay with 24-hour esophageal $\mathrm{pH}$ monitoring for detection of gastric reflux into the proximal esophagus, oropharynx, and lung. Dig Dis Sci 2003; 48: 1813-1817.

20. Tasker A, Dettmar PW, Panetti M, Koufman JA, Birchall JP, Pearson JP. Is gastric reflux a cause of otitis media with effusion in children? Laryngoscope 2002; 112: 1930-1934.

21. Ward C, Forrest IA, Brownlee IA, et al. Pepsin like activity in bronchoalveolar lavage fluid is suggestive of gastric aspiration in lung allografts. Thorax 2005; 60: 872-874.

22. Stovold R, Forrest IA, Corris PA, et al. Pepsin, a biomarker of gastric aspiration in lung allografts: A putative association with rejection. Am J Respir Crit Care Med 2007; 175: 1298-1303.

23. Vos R, Blondeau K, Vanaudenaerde BM, et al. Airway Colonization and Gastric Aspiration After Lung Transplantation: Do Birds of a Feather Flock Together? $J$ Heart Lung Transplant 2008; 27: 843-849.

24. D'Ovidio F, Mura M, Tsang M, et al. Bile acid aspiration and the development of bronchiolitis obliterans after lung transplantation. J Thor Cardiov Surg 2005; 129: 1144-1152.

25. Dent J, El-Serag HB, Wallander MA, Johansson S. Epidemiology of gastro-oesophageal reflux disease: A systematic review. Gut 2005; 54: 710-717.

26. El-Serag HB, Sonnenberg A. Comorbid occurrence of laryngeal or pulmonary disease with esophagitis in United States military veterans. Gastroenter 1997; 113: 755-760.

27. Avidan B, Sonnenberg A, Schnell TG, Sontag SJ. Risk factors for erosive reflux esophagitis: A case-control study. Am J Gastroenter 2001; 96: 41-46.

28. Bulmer DM, Ali MS, Brownlee IA, Dettmar PW, Pearson JP. Laryngeal mucosa: Its susceptibility to damage by acid and pepsin. Laryngoscope 2010; 120: 777782.

29. Bulmer D, Ross PE, Axford SE, et al. Cell biology of laryngeal epithelial defenses in health and disease: Further studies. Ann Otol, Rhinol Laryngol 2003; 112: 481-491.

30. Strohmaier W and Schlag G. Lung lavage with diluted surfactant is as effective as bolus treatment in a rabbit long-term aspiration model. Appl Cardiopul Path 1997; 7: 17-22.

31. Ohrui T, Yamaya M, Suzuki T, et al. Mechanisms of gastric juice-induced hyperpermeability of the cultured human tracheal epithelium. Chest 1997; 111: 454-459.

32. Waldum HL, Qvigstad G, Fossmark R, Kleveland PM, Sandvik AK. Rebound acid hypersecretion from a physiological, pathophysiological and clinical viewpoint. Scand J Gastroenter 2010; 45: 389-394.

33. Yao X, Forte JG. Cell Biology of Acid Secretion by the Parietal Cell. Ann Rev Physiol 2003; 65: 103131.

34. Kageyama T. Pepsinogens, progastricsins, and prochymosins: Structure, function, evolution, and development. Cell Mol Life Sci 2002; 59: 288-306.

35. Davies DR. The structure and function of the aspartic proteinases. Ann Rev Biophysics Biophysical Chem 1990; 19: 189-215.

36. Trauner M and Boyer JL. Bile salt transporters: Molecular characterization, function, and regulation. Phys Rev 2003; 83: 633-671.

37. Hofmann AF. The continuing importance of bile acids in liver and intestinal disease. Arch Intern Med 1999; 159: 2647-2658.

38. Kauer WKH, Peters JH, DeMeester TR, et al. Mixed reflux of gastric and duodenal juices is more harmful to the esophagus than gastric juice alone: The need for surgical therapy re- emphasized. Ann Surgery 1995; 222: 525-533.

39. Numans ME, Lau J, De Wit NJ, Bonis PA. Short-term treatment with proton-pump inhibitors as a test for gastroesophageal reflux disease: a meta-analysis of diagnostic test characteristics. Ann Intern Med 2004; 140: 518-527+I51

40. Chiba N, De Gara CJ, Wilkinson JM, Hunt RH. Speed of healing and symptom relief in grade II to IV gas- 
troesophageal reflux disease: A meta-analysis. Gastroenter 1997; 112: 1798-1810.

41. Gursoy O, Memis D, Sut N. Effect of proton pump inhibitors on gastric juice volume, gastric $\mathrm{pH}$ and gastric intramucosal $\mathrm{pH}$ in critically ill patients: A randomized, double-blind, placebo-controlled study. Clin Drug Invest 2008; 28: 777-782.

42. Raeder J, Dahl V, Bjoernestad E, et al. Does esomeprazole prevent post-operative nausea and vomiting? Acta Anaesth Scand 2007; 51: 217-225.

43. Nishina K, Mikawa K, Maekawa N, Takao Y, Shiga M, Obara H. A comparison of lansoprazole, omeprazole, and ranitidine for reducing preoperative gastric secretion in adult patients undergoing elective surgery. Anesth Analg 1996; 82: 832-836.

44. Turco R, Martinelli M, Miele E, et al. Proton pump inhibitors as a risk factor for paediatric Clostridium difficile infection. Alim Pharmac Ther 2010; 31: 754759.

45. Lombardo L, Foti M, Ruggia O, Chiecchio A. Increased Incidence of Small Intestinal Bacterial Overgrowth During Proton Pump Inhibitor Therapy. Clin Gastroenter Hepat 2010; 8: 504-508.

46. Canani RB, Cirillo P, Roggero P, et al. Therapy with gastric acidity inhibitors increases the risk of acute gastroenteritis and community-acquired pneumonia in children. Pediatrics 2006; 117: e817-e820.

47. Laheij RJF, Sturkenboom MCJM, Hassing RJ, Dieleman J, Stricker BHC, Jansen JBMJ. Risk of community-acquired pneumonia and use of gastric acid-suppressive drugs. J Am Med Ass 2004; 292: 1955-1960.

48. Cunningham R, Dale B, Undy B, Gaunt N. Proton pump inhibitors as a risk factor for Clostridium difficile diarrhoea. J Hosp Infec 2003; 54: 243-245.

49. Vesper BJ, Jawdi A, Altman KW, Haines Iii GK, Tao L, Radosevich JA. The effect of proton pump inhibitors on the human microbiota. Cur Drug Met 2009; 10: 84-89.

50. Knowles MR, Boucher RC. Mucus clearance as a primary innate defense mechanism for mammalian airways. J Clin Invest 2002; 109: 571-577.

51. Rose MC, Voynow JA. Respiratory tract mucin genes and mucin glycoproteins in health and disease. Phys Rev 2006; 86: 245-278.

52. Williams OW, Sharafkhaneh A, Kim V, Dickey BF, Evans CM. Airway mucus: From production to secretion. Am J Resp Cell Mol Biol 2006; 34: 527-536.

53. Yuta A, Ali M, Sabol M, Gaumond E, Baraniuk JN. Mucoglycoprotein hypersecretion in allergic rhinitis and cystic fibrosis. Am J Phys - Lung Cell Mol Phys 1997; 273: L1203-L1207.

54. Arbour NC, Lorenz E, Schutte BC, et al. TLR4 mutations are associated with endotoxin hyporesponsiveness in humans. Nat Gen 2000; 25: 187-191.

55. Eisenbarth SC, Piggott DA, Huleatt JW, Visintin I, Herrick CA, Bottomly K. Lipopolysaccharide-enhanced, toll-like receptor 4-dependent $\mathrm{T}$ helper cell type 2 responses to inhaled antigen. J Exp Med 2002; 196: 1645-1651.

56. Ricciardolo FLM, Gaston B, Hunt J. Acid stress in the pathology of asthma. J All Clin Immunol 2004; 113: 610-619.

57. Ferrari M, Olivieri M, Sembenini C, et al. Tussive effect of capsaicin in patients with gastroesophageal reflux without cough. Am J Respir Crit Care Med 1995; 151: 557-561.

58. McGarvey LPA, Forsythe P, Heaney LG, MacMahoir $\mathrm{J}$, Ennis M. Bronchoalveolar lavage findings in patients with chronic nonproductive cough. Eur Respir J 1999; 13: 59-65.
59. Capello A, Moons LMG, Van De Winkel A, et al. Bile acid-stimulated expression of the farnesoid $\mathrm{X}$ receptor enhances the immune response in Barrett esophagus. Am J Gastroenter 2008; 103: 1510-1516.

60. Johnston N, Wells CW, Blumin JH, Toohill RJ, Merati AL. Receptor-mediated uptake of pepsin by laryngeal epithelial cells. Ann Otol Rhinol Laryngol 2007; 116: 934-938.

61. Wiener GJ, Tsukashima R, Kelly C, et al. Oropharyngeal $\mathrm{pH}$ Monitoring for the Detection of Liquid and Aerosolized Supraesophageal Gastric Reflux. J Voice 2009; 23: 498-504.

62. Montuschi P. Analysis of exhaled breath condensate in respiratory medicine: Methodological aspects and potential clinical applications. Ther Advan Resp Dis 2007; 1: 5-23.

63. Dent J. Pathogenesis of gastro-oesophageal reflux disease and novel options for its therapy. Neurogastroenter Motil 2008; 20: 91-102.

64. Zerbib F, Bruley Des Varannes S, Roman S, et al. Normal values and day-to-day variability of 24-h ambulatory oesophageal impedance-pH monitoring in a Belgian-French cohort of healthy subjects. Alim Pharmac Ther 2005; 22: 1011-1021.

65. Schneider JH, Kuper MA, Konigsrainer A, Brucher BLDM. Transient Lower Esophageal Sphincter Relaxation and Esophageal Motor Response. J Surg Res 2010; 159: 714-719.

66. Lehmann A, Antonsson M, Holmberg AA, et al. (R)(3-amino-2-fluoropropyl) phosphinic acid (AZD3355), a novel GABA B receptor agonist, inhibits transient lower esophageal sphincter relaxation through a peripheral mode of action. J Pharmac Exper Therap 2009; 331: 504-512.

67. Pandolfino JE, Ghosh SK, Zhang Q, Han A, Kahrilas PJ. Upper sphincter function during transient lower oesophageal sphincter relaxation (tLOSR); It is mainly about microburps. Neurogastroenter Motil 2007; 19: 203-210.

68. Scheffer RCH, Akkermans LMA, Bais JE, Roelofs JMM, Smout AJPM. Gooszen HG, Elicitation of transient lower oesophageal sphincter relaxations in response to gastric distension and meal ingestion. Neurogastroenter Motil 2002; 14: 647-655.

69. Trudgill NJ, Riley SA. Transient lower esophageal sphincter relaxations are no more frequent in patients with gastroesophageal reflux disease than in asymptomatic volunteers. Am J Gastroenter 2001; 96: 25692574.

70. Kahrilas PJ, Shi G, Manka M, Joehl RJ. Increased frequency of transient lower esophageal sphincter relaxation induced by gastric distention in reflux patients with hiatal hernia. Gastroenter 2000; 118: 688-695.

71. Kahrilas PJ, Lin S, Chen J, Manka M. The effect of hiatus hernia on gastro-oesophageal junction pressure. Gut 1999; 44: 476-482.

72. Frankhuisen R, Van Herwaarden MA, Scheffer RC, Hebbard GS, Gooszen HG, Samsom M. Increased intragastric pressure gradients are involved in the occurrence of acid reflux in gastroesophageal reflux disease. Scand J Gastroenter 2009; 44: 545-550.

73. Beaumont H, Bennink RJ, De Jong J, Boeckxstaens GE. The position of the acid pocket as a major risk factor for acidic reflux in healthy subjects and patients with GORD. Gut 2010; 59: 441-451.

74. Brownlee IA. The physiological roles of dietary fibre. Food Hydrocolloids 2010; in Press.

75. Sanger GJ, Lee K. Hormones of the gut-brain axis as targets for the treatment of upper gastrointestinal disorders. Nat Reviews Drug Disc 2008; 7: 241-254. 
76. Herranz R. Cholecystokinin antagonists: Pharmacological and therapeutic potential. Med Res Rev 2003; 23: 559-605.

77. Field SK, Underwood M, Brant R, Cowie RL. Prevalence of gastroesophageal reflux symptoms in asthma. Chest 1996; 109: 316-322.

78. Sontag SJ, O'Connell S, Khandelwal S, et al. Most asthmatics have gastroesophageal reflux with or without bronchodilator therapy. Gastroenter 1990; 99: 613620.

79. Gislason $\mathrm{T}$, Janson C, Vermeire $\mathrm{P}$, et al. Respiratory symptoms and nocturnal gastroesophageal reflux: A population-based study of young adults in three european countries. Chest 2002; 121: 158-163.

80. Ayres JG. Oesophageal reflux and asthma. Monaldi Arch Chest Med 1995; 50: 469-471.

81. Avidan B, Sonnenberg A, Schnell TG, Sontag SJ. Temporal associations between coughing or wheezing and acid reflux in asthmatics. Gut 2001; 49: 767772.

82. Condino AA, Sondheimer J, Pan Z, Gralla J, Perry D, O'Connor JA. Evaluation of gastroesophageal reflux in pediatric patients with asthma using impedance- $\mathrm{pH}$ monitoring. J Ped 2006; 149: 216-219.e1.

83. Blondeau K, Dupont LJ, Mertens V, et al. Gastro-oesophageal reflux and aspiration of gastric contents in adult patients with cystic fibrosis. Gut 2008; 57: 10491055.

84. Sifrim D, Dupont L, Blondeau K, Zhang X, Tack J, Janssens J. Weakly acidic reflux in patients with chronic unexplained cough during 24 hour pressure, $\mathrm{pH}$, and impedance monitoring. Gut 2005; 54: 449-454.

85. Morice AH, Fontana GA, Sovijarvi ARA, et al. The diagnosis and management of chronic cough. Eur Respir J 2004; 24: 481-492.

86. Tatar M, Karcolova D, Pecova R, Kollarik M, Plevkova J, Brozmanova M. Experimental modulation of the cough reflex. Eur Respir Rev 2002; 12: 264-269.

87. Suskind DL, Thompson DM, Gulati M, Huddleston P, Liu DC, Baroody FM. Improved infant swallowing after gastroesophageal reflux disease treatment: A function of improved laryngeal sensation? Laryngoscope 2006; 116: 1397-1403.

88. Phua SY, McGarvey LPA, Ngu MC, Ing AJ. Patients with gastro-oesophageal reflux disease and cough have impaired laryngopharyngeal mechanosensitivity. Tho$\operatorname{rax} 2005$; 60: 488-491

89. Willging JP, Thompson DM. Pediatric FEESST: Fiberoptic endoscopic evaluation of swallowing with sensory testing. Curr Gastroenter Reports 2005; 7 : 240-243.

90. Boesch RP, Shah P, Vaynblat M, et al. Relationship between upper airway obstruction and gastroesophageal reflux in a dog model. J Invest Surg 2005; 18: 241-245.

91. Eskiizmir G, Kezirian E. Is there a vicious cycle between obstructive sleep apnea and laryngopharyngeal reflux disease? Med Hypotheses 2009; 73: 706-708.

92. Robertson AG, Ward C, Pearson JP, et al. Longitudinal changes in gastro-oesophageal reflux from 3 months to 6 months after lung transplantation. Thorax 2009; 64: 1005-1007.

93. Belperio III JA, Weigt SS, Fishbein MC, Lynch Iii JP. Chronic lung allograft rejection: Mechanisms and therapy. Proc Am Thor Soc 2009; 6: 108-121.

94. Ward C, Snell GI, Zheng L, et al. Endobronchial biopsy and bronchoalveolar lavage in stable lung transplant recipients and chronic rejection. Am J Respir Crit Care Med 1998; 158: 84-91.

95. Zheng L, Ward C, Snell GI, et al. Scar collagen depo- sition in the airways of allografts of lung transplant recipients. Am J Respir Crit Care Med 1997; 155: 2072 2077.

96. Jeffery PK. Remodeling and inflammation of bronchi in asthma and chronic obstructive pulmonary disease. Proc Am Thor Soc 2004; 1: 176-183.

97. Massague J. TGF-beta signal transduction. Ann Rev Biochem 1998; 67: 753-791.

98. El-Gamel A, Sim E, Hasleton P, et al. Transforming growth factor beta (TGF-beta) and obliterative bronchiolitis following pulmonary transplantation. J Heart Lung Transplant 1999; 18: 828-837.

99. Ward C, Forrest IA, Murphy DM, et al. Phenotype of airway epithelial cells suggests epithelial to mesenchymal cell transition in clinically stable lung transplant recipients. Thorax 2005; 60: 865-871.

100. Zeisberg M, Neilson EG. Biomarkers for epithelialmesenchymal transitions. J Clin Invest 2009; 119: 1429-1437.

101. Perng DW, Chang KT, Su KC, et al. Exposure of airway epithelium to bile acids associated with gastroesophageal reflux symptoms: A relation to transforming growth factor- $\beta_{1}$ production and fibroblast proliferation. Chest 2007; 132: 1548-1556.

102. Borthwick LA, Parker SM, Brougham KA, et al. Epithelial to mesenchymal transition (EMT) and airway remodelling after human lung transplantation. Thorax 2009; 64: 770-777.

103. Robertson AGN, Griffin SM, Murphy DM, et al. Targeting allograft injury and inflammation in the management of post-lung transplant bronchiolitis obliterans syndrome. Am J Transplant 2009; 9: 1272-1278.

104. Wildi SM, Tutuian R, Castell DO. The influence of rapid food intake on postprandial reflux: Studies in healthy volunteers. Am J Gastroenter 2004; 99: 16451651.

105. Zentilin P, Iiritano E, Dulbecco P, et al. Normal values of 24-h ambulatory intraluminal impedance combined with $\mathrm{pH}$-metry in subjects eating a Mediterranean diet. Digestive and Liver Dis 2006; 38: 226-232.

106. Bredenoord AJ, Weusten BLAM, Timmer R, Smout AJPM. Reproducibility of multichannel intraluminal electrical impedance monitoring of gastroesophageal reflux. Am J Gastroenter 2005; 100: 265-269.

107. Shay S, Tutuian R, Sifrim D, et al. Twenty-four hour ambulatory simultaneous impedance and $\mathrm{pH}$ monitoring: A multicenter report of normal values from 60 healthy volunteers. Am J Gastroenter 2004; 99: 10371043.

108. Foster C, Aktar A, Kopf D, Zhang P, Guttentag S. Pepsinogen C: A type 2 cell-specific protease. Am J Phys - Lung Cell Mol Phys 2004; 286: L382-L387.

109. Axford SE, Sharp N, Dettmar PW, et al. Cell biology of laryngeal epithelial defenses in health and disease: Preliminary studies. Ann Otol, Rhinol Laryngol 2001; 110: 1099-1108.

110. Gill GA, Johnston N, Buda A, et al. Laryngeal epithelial defenses against laryngopharyngeal reflux: Investigations of E-cadherin, carbonic anhydrase isoenzyme III, and pepsin. Ann Otol, Rhinol Laryngol 2005; 114: 913-921.

111. Aviv JE, Kim T, Thomson JE, Sunshine S, Kaplan S, Close LG. Fiberoptic endoscopic evaluation of swallowing with sensory testing (FEESST) in healthy controls. Dysphagia 1998; 13: 87-92.

112. Nishino T. The role of the larynx in defensive airway reflexes in humans. Eur Respir Rev 2002; 12: 231-235.

113. Jean A. Brain stem control of swallowing: Neuronal network and cellular mechanisms. Phys Rev 2001; 81: 929-969. 
114. Robertson AGN, Ward C, Pearson JP, Corris PA, Dark JH, Griffin SM. Lung Transplantation, Gastroesophageal Reflux, and Fundoplication. Ann Thor Surg 2010; 89: 653-660.

115. Bruno IG, Jin W, Cote GJ. Correction of aberrant
FGFR1 alternative RNA splicing through targeting of intronic regulatory elements. Hum Mol Gen 2004; 13: 2409-2420.

116. Riss T, Moravec R. Introducing the CellTiter-Blue ${ }^{\mathrm{TM}}$ Cell Viability Assay. Promega Notes 2003; 83: 10 -13.

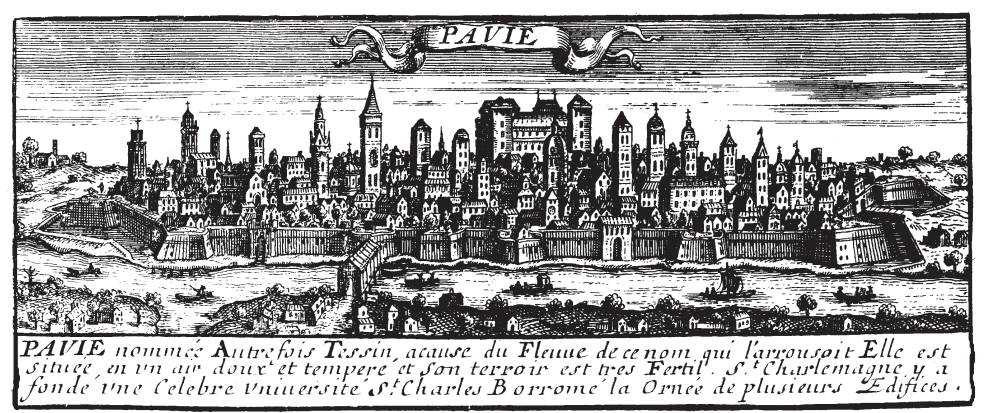

